\section{Sentir-se pai: a vivência masculina sob o olhar de gênero}

\author{
Fatherhood: the male experience \\ from a gender focus
}

1 Centro de Ciências da
Saúde, Universidade
Federal da Paraíba,
João Pessoa, Brasil.
2 Escola de Enfermagem,
Universidade Federal da
Bahia, Salvador, Brasil.
Correspondência
W. M. F. Freitas
Centro de Ciências da Saúde,
Universidade Federal da
Paraíba.
Rua Joséda Costa Gomes 44,
João Pessoa, PB
58075-405, Brasil.
waglaniafreitas@yahoo.com.br

\begin{abstract}
Pregnant and postpartum women frequently complain about the limited involvement of their partners with their children, beginning in pregnancy. The current study thus aimed to understand men's feelings towards fatherhood during this period of their lives. The research adopted a qualitative approach and a gender-theory focus. The universe included men whose children were being treated at a pediatric outpatient clinic, and data were collected through semistructured home interviews. Subjects' testimony was analyzed using discourse analysis, the basic principle of which is to recognize the most abstract levels of the text, identified by themes organized in blocks of meaning and allowing the construction of empirical categories. Study subjects' social position towards fatherhood shows that the model that men assume as father-providers coexists with that of the man who seeks to be a "new father", whose affective bond with the son or daughter begins during pregnancy, thus representing a break with traditional fatherhood.
\end{abstract}

Paternity; Reproductive Medicine; Gender Identity
Waglânia de Mendonça Faustino e Freitas 1

Edméia de Almeida Cardoso Coelho 2

Ana Tereza Medeiros Cavalcanti da Silva 1

\section{Introdução}

A gestação e o nascimento constituem para a mulher e para o homem fases de mudanças, com transformações e incertezas que acompanham a aquisição de novos papéis e responsabilidades antes inexistentes, incluindo-se as relacionadas com os(as) filhos(as), com a casa e com os demais membros da família. Assim, a paternidade e a maternidade são permeadas por conflitos determinados pela situação nova que o casal vivencia. Uma gravidez em curso pode gerar diferentes sentimentos, vividos pelos casais de forma única: alegria, tristeza, satisfação e insatisfação. Para alguns casais, essa fase traz alegrias e o desejo de conviver harmoniosamente. Para outros, conflitos anteriores acentuam-se, muitos deles relacionados com o modo como homens e mulheres compreendem e desempenham seus atributos sociais.

Na gravidez, o homem e a mulher deixam de ser apenas filho e filha para se tornarem pai e mãe, ambos vivenciando essa transição com expectativas, anseios e temores. O homem também sofre o impacto da mudança de papéis. $\mathrm{O}$ medo, a responsabilidade sobre o bebê que está no ventre da companheira, as alterações no comportamento dela, muitas vezes sem uma causa aparente, também levam o homem a viver uma fase conflituosa. Para muitos homens, sentir-se pai é um fato que só ocorre posteriormente ao nascimento e, em alguns casos, mesmo após a 
chegada do filho ou da filha, o sentimento de paternidade ainda não é tão perceptível, assim como o peso da responsabilidade que esse evento pressupõe.

Assim, no experienciar da paternidade, poderá ocorrer o distanciamento de muitos homens do processo da gravidez, com possibilidade de se manter após o parto, estando relacionado com a ambivalência presente nesse período. Questões emocionais, culturais, religiosas e familiares permearão a vivência da paternidade como experiência desejada ou não desejada, desejável ou não desejável, ditando como será estabelecida a relação entre homem-mulher e com o(a) filho(a).

A reprodução social dos modelos masculino e feminino tem a sua base na maternagem ( $m o-$ thering), termo que significa cuidados de mãe, cujo valor cultural na reprodução da masculinidade tem um sentido ideológico na produção das desigualdades entre os sexos. Sendo assim, as mulheres, como mães, são agentes decisivos na esfera da reprodução social, pois são elas que educam e repassam aos filhos as ideologias vigentes na sociedade 1 .

$\mathrm{Na}$ vida familiar, a divisão entre o que compete ao masculino e ao feminino é transmitida como um valor culturalmente determinado e aceito, pois: "Homem, masculino e pai são qualificações que definem um modo de inserção do sujeito na cultura da qual ele faz parte (...) juntas definem um padrão de comportamento a ser seguido pelos homens" 2 (p. 151). Assim, para que os homens experienciem a paternidade de modo equânime e não apenas mais participativo, é preciso que homens e mulheres repensem seus atributos sociais em meio à complexidade dessa vivência, reconhecendo que a paternidade constitui uma oportunidade de homens ampliarem suas dimensões internas e renovarem sua relação com a vida 2 .

Mulheres grávidas e puérperas revelam que o distanciamento do homem dos processos de gestação e parto gera nas mulheres sentimento de solidão e vazio. Tais processos são acentuados pela falta de espaço para os homens participarem do processo gravídico desde o pré-natal. Há necessidade de planejamento de ações institucionais específicas para essa população, a fim de oferecer suporte nas situações de conflito geradas pela gravidez e nascimento dos filhos, de modo que os homens possam se tornar referência de apoio emocional às suas companheiras 3. Iniciativas vêm sendo adotadas no sentido de estimular a participação masculina no processo gestacional, parto, puerpério, amamentação e demais eventos que envolvem a relação pai, mãe e filhos(as), merecendo destaque o trabalho do Instituto PAPAI (http://www.papai.org.br).
$\mathrm{Na}$ atualidade, há um aprofundamento na complexidade das relações conjugais que comporta a organização de eventos, nos quais os homens estão discutindo sua própria identidade social. Isso representa uma tentativa de compreender e encontrar soluções para as novas situações de relacionamento decorrentes das mudanças nas relações parentais e da ampliação da participação das mulheres na esfera pública de trabalho, fatores relevantes no relacionamento homem/mulher do cenário social contemporâneo.

$\mathrm{O}$ cotidiano do cuidado à saúde da mulher vem mostrando que a relação com o parceiro sexual influencia profundamente o bem-estar da mulher na gestação e após o nascimento dos(as) filhos(as), seja pela sua presença, aceitação e prazer de estar junto, seja pela sua ausência, resistência e negação da responsabilidade como pai. Quando a participação do homem é efetiva, na gravidez e após o parto, criam-se situações de bem-estar para todos os envolvidos no processo, de modo a se estabelecerem relações mais igualitárias.

Em investigação científica com grupos de casais grávidos, vimos que, para várias mulheres, a participação do homem na gravidez e após o nascimento se restringia à manutenção financeira, cabendo às mulheres toda a responsabilidade com a casa e com o cuidado dos filhos, o que gerava necessidade de apoio e atenção. Por outro lado, o discurso masculino surpreendia, pois alguns homens consideravam desempenhar bem o seu papel e até afirmavam que conseguiam superar as expectativas da companheira ${ }^{4}$.

Resultados de pesquisa, observações empíricas e o contexto atual de transformação das relações de gênero em que se insere a paternidade motivaram investigação científica desenvolvida em dissertação de mestrado 5 , tendo como um dos objetivos compreender a emergência do sentimento de paternidade a partir de experiências vivenciadas por homens na gestação e após o nascimento dos(as) filhos(as), resultando em categoria empírica divulgada neste artigo.

\section{Metodologia}

A paternidade é exercida sob referenciais de masculinidade e de feminilidade que orientam as representações ideológicas hierarquizantes dos papéis sociais de homens e mulheres, a partir das diferenças biológicas existentes entre os sexos. Desse modo, o estudo comporta a adoção da abordagem qualitativa e o enfoque teórico de gênero, para a compreensão do seu objeto.

Os sujeitos da investigação foram dez homens, cujos filhos eram atendidos no ambula- 
tório de puericultura de um hospital escola, em João Pessoa, Paraíba, Brasil, sendo assim definido pela facilidade de acesso ao campo para as pesquisadoras. No artigo foram usados os depoimentos de sete pais, tendo em vista a contribuição dos demais ser mais efetiva em outra categoria analisada e ainda não divulgada. $\mathrm{O}$ grupo foi selecionado pelos seguintes critérios: residir na região da grande João Pessoa; ter pelo menos mais de um filho com a companheira, por possibilitar experiência mais ampla com a paternidade; morar na mesma residência dos filhos e da companheira; aceitar participar do estudo; autorizar o uso do gravador; assinar o Termo de Consentimento Livre e Esclarecido.

O contato com os pais foi feito por ocasião de sua presença no ambulatório ou intermediado por sua companheira que agendava conosco uma visita domiciliar ao parceiro, após sua concordância, antecedida por contato telefônico para confirmação, no caso dos que dispunham desse meio de comunicação. Para os demais sujeitos da investigação, a confirmação de sua concordância em participar da pesquisa dava-se por ocasião da visita domiciliar. Todos os contatados aceitaram participar do estudo.

O material empírico foi produzido por meio da técnica de entrevista, com um roteiro semiestruturado que continha as questões norteadoras. Foram realizadas no período de dois meses - março e abril de 2003 - em horários e locais escolhidos pelos participantes, dentre os quais residências e locais de trabalho. Os sujeitos foram estimulados a falar do momento em que se sentiram pais, das responsabilidades que adquiriram e do significado que a experiência com a paternidade confere ao homem no espaço doméstico.

A média de idade dos participantes do estudo foi de 25 anos, variando de 20 a 33 anos. O tempo médio de relacionamento com a parceira foi de 4,5 anos, predominando a união consensual. Os pais tinham entre 1 a 3 filhos, cuja idade variou de vinte dias de nascido até oito anos. Suas ocupações foram: estoquista, entregador de hortaliças, agente penitenciário, radialista, restaurador de patrimônio, atendente de vendas. Dos dez participantes, quatro estavam desempregados. A renda mensal oscilou entre um e seis salários mínimos, sendo o salário mínimo na época do estudo R\$ 200,00 (Duzentos Reais). Por ocasião da pesquisa, os homens eram os provedores da família, à exceção de um. Todos os participantes eram alfabetizados, sendo o ensino fundamental incompleto e o ensino médio incompleto os graus de escolaridade predominantes. Apenas um dos entrevistados cursava o ensino superior por ocasião da entrevista.
Os depoimentos dos sujeitos do estudo foram analisados pela técnica de análise do discurso, proposta por Fiorin ${ }^{6}$. O autor considera que o texto é uma organização dotada de mecanismos de coerência interna e externa, nos quais se podem perceber as visões de mundo dos sujeitos discursistas. Assim, o texto é um objeto integralmente lingüístico e histórico. Lingüístico porque determinado por regras gramaticais; histórico, porque seu sentido é dado, também, por suas relações com o exterior, ou seja, com as concepções e com as visões de mundo que existem na sociedade da época em que ele foi produzido. Por isso, o texto é um objeto individual e um todo organizado de sentidos, num determinado universo de significação. Quanto ao discurso, é uma posição social, porque materializa na linguagem e veicula na sociedade as representações ideológicas dos sujeitos discursistas 6 .

Seguindo os movimentos preconizados por Fiorin 6 depois de produzidos os textos, partimos para a identificação dos temas e figuras, das fases da narrativa e dos temas recorrentes, para a composição dos blocos de significados e construção das subcategorias e categorias empíricas correspondentes. $\mathrm{O}$ agrupamento dos temas revelou as contradições e a dinâmica de transição do modelo de pai tradicional/novo pai, levando à formulação de categorias empíricas, sendo divulgada neste artigo a dimensão afetiva da paternidade que emergiu com o sentir-se pai.

Consideramos as diretrizes para pesquisa com seres humanos, que visam à proteção dos direitos dos envolvidos na pesquisa, conforme os aspectos éticos apontados pela Resolução $n$. 196/96 do Conselho Nacional de Saúde. Por ocasião do convite aos homens para participação na pesquisa, foi-lhes garantido: anonimato, sigilo sobre suas informações, direito de desistência em qualquer etapa da pesquisa, acesso às pesquisadoras e aos resultados do estudo. Foi-lhes também solicitado que escolhessem para si um nome com o qual se identificassem e que pudesse ser-lhes atribuído no texto da pesquisa. Desse modo, todos os nomes encontrados no texto são fictícios.

\section{A dimensão afetiva da paternidade: do pai biológico ao "novo pai"}

Os posicionamentos assumidos pelos participantes acerca da paternidade variaram em grau, natureza e intensidade. Para alguns, o sentir-se pai emergiu com a notícia da gravidez, passando por aqueles que só se perceberam pais em estágio mais avançado da gestação quando os movimentos fetais eram perceptíveis; aqueles cuja 
paternidade foi sentida com o nascimento do(a) filho(a) e outro em que o ser pai foi sendo construído anos após o nascimento do(a) filho(a).

No que tange ao sentimento de paternidade tendo como referência a notícia da gravidez e o processo vivido a partir dela, posicionamentos de sujeitos do estudo revelaram que, a paternidade foi uma experiência social significativa desde o momento em que tomaram conhecimento da gravidez, traduzindo-se, mais objetivamente para um deles, em satisfação, bem-estar e afeto pela parceira, sendo vivido como um momento especial, que mereceu ser celebrado: "O sentimento de pai (...) desde o momento que a gente foi no consultório e eu fiquei sabendo que ela estava grávida. Fiz até festa. Ela estava com dois meses e dez dias (...) Eu fiz um bolinho (...) guaraná..." (Pedro).

No depoimento a seguir, a paternidade aparece como um sentimento percebido desde a notícia da gravidez, inscrito na subjetividade do sujeito, de difícil explicitação por mecanismos objetivos, preservando o mistério que o circunda: "Senti-me pai (...) desde que ela engravidou, porque eu me senti diferente. Depois que ela me disse que estava grávida, achei diferente. Mudou pra mim. Mudou tudo. A minha vida mudou toda. Acho que mudou" (João).

Nos depoimentos em análise, a paternidade é sentida ainda quando o bebê é imperceptível. As reações dos homens podem ser analisadas sob dois ângulos: um que recria a função paterna, com ênfase na dimensão afetiva, vinculando pai, mãe e filho desde a notícia da gravidez; outro relacionado à expectativa social de garantir a virilidade masculina presente no desejo manifesto ou latente de viver a paternidade, por esta garantir ao homem o cumprimento de uma função social, a de reprodução da espécie.

No que diz respeito à relação afetiva enunciada, ela pode ser discutida à luz de gênero. Os homens tentam viver a experiência do ser pai, rompendo estereótipos do passado e se aproximando dos aspectos afetivos dessa relação de modo que ser pai compreendido como ser provedor dá espaço para a emoção e afeto 7 . Analisando tal relação afetiva sob o enfoque da psicologia, estudos nessa área apontam a importância do estabelecimento precoce do vínculo pai-filho(a) 8 influenciando qualitativamente o desenvolvimento emocional mais saudável, minimizando possíveis rivalidades, somatizações e regressões. Desde cedo, o feto apresenta padrões de comportamento e características de personalidades bem definidas, cuja comunicação e interação podem acontecer por atos, pensamentos ou palavras 7. Além disso, a gestação configura-se como um período de preparação para novos atributos sociais tanto para a mãe quanto para o pai ${ }^{9}$. Assim, quanto mais fortes forem os laços afetivos fixados entre pai e filho(a) na gravidez, melhor será o desenvolvimento da paternidade e do vínculo pai-filho(a) na vida fora do útero, sendo o estabelecimento desses laços, nos primeiros estágios de vida, a chave para reviver a instituição da paternidade.

A participação do homem na gravidez o faz sentir-se parte do processo e se reflete na qualidade de vida do casal, possibilitando relações menos conflituosas também com a mulher. A esse respeito, pode-se afirmar que os pais mais conectados emocionalmente à gestação estariam mais predispostos a reagir adequadamente às necessidades de apoio e compreensão de suas esposas ${ }^{9}$. Estudos sobre a percepção precoce da paternidade relatam envolvimento emocional e comportamental desde os primeiros estágios da gestação 9,10,11.

Particularizando a análise do depoimento de João, a gravidez modificou-o como homem, fazendo-o sentir-se diferente, de modo que a satisfação que lhe proporcionou está expressa em seu discurso. O sentir-se diferente, referido pelo sujeito da investigação, remete-nos também aos significados sociais da paternidade, entre eles o cumprimento de um dever, ao certificar-se de que é capaz de fecundar uma mulher e de se confirmar macho, reprodutor e viril, trazendo implícito o ser pai como espaço de reconhecimento de poder e honra. Desse modo, a paternidade pode ser concebida como fundamental para reafirmar a masculinidade em uma relação estável 7 , sendo recriada com a incorporação da paternidade e de suas responsabilidades.

Todavia, a paternidade é vivenciada e compreendida de formas diversas e em diferentes fases do processo da gravidez, podendo delinearse, à medida que ela evolui, e a nova vida é percebida pelos movimentos do bebê, conforme se lê a seguir: "Não sei nem dizer assim, faz um bocado de tempo já. Eu estava em Natal no período que ela estava grávida, trabalhando lá (...) Sentia-me pai só que não tanto quanto quando estando juntos. Não sentia muito porque eu não estava perto dela (...) Ah! Quando o nenê começou a se mexer na barriga, que eu sentia, quando vinha pra casa e no dia do nascimento" (Carlos).

Nesse depoimento, o sentimento de paternidade apresenta-se incipiente no início da gravidez e dependente da proximidade física do casal. Considerando as dificuldades de homens elaborarem mental e afetivamente a gravidez e a paternidade, sua incorporação pelo pai Carlos acontece somente quando a gravidez avança e ele percebe a vida do(a) filho(a) pelos movimentos fetais, concretizando-se o bebê imaginário 
pouco a pouco na vida do pai. A posição social presente no discurso em análise corrobora conhecimentos produzidos sobre o tema, que afirmam a paternidade como uma construção produzida, à proporção que o homem participa da gravidez e percebe o crescimento da barriga da parceira, considerando ser essa representação diretamente proporcional à identificação do homem como pai, que começa a construir a figura do(a) filho(a), ainda muito abstrato comparado com a concreta realização da paternidade 7,9.

Nesse sentido, para que o homem sinta-se pai antes do nascimento do(a) filho(a) é necessário, além da proximidade física com a gestante, o envolvimento afetivo e aceitação da gravidez, além da necessidade de ter sido construída como projeto no passado 7 , mesmo que esse projeto fosse para um outro momento. Nos depoimentos em que a paternidade é vivenciada pelos homens desde a gravidez, há o discurso de busca do "novo pai", que rompe o modelo tradicional de paternidade, desenvolvendo sentimentos afetivos e de vínculo que favorecem a construção do trinômio pai-mãe-filho(a). Esses sujeitos sociais afastam-se do modelo tradicional de homens rígidos e distantes, ao compartilhar da experiência que é vivida no corpo da companheira 12,13. Essa aproximação com o(a) filho(a), já na gravidez, vem sendo buscada especialmente pelos homens jovens, delineando-se um modelo de pai que rompe estereótipos patriarcais 14. Esse "novo pai" participa da gravidez, compartilhando as alegrias do nascimento e as tarefas diárias outrora reservadas culturalmente e exclusivamente às mulheres 11,12,13.

Entretanto, é o nascimento do filho que representa o auge de um processo que se inicia na gravidez, visto como o momento em que o bebê sai do imaginário masculino e passa a ser representado como vida concreta, confirmada pela possibilidade de tê-lo nos braços, fato que marca pela emoção, ao mesmo tempo em que remete a deveres, como as responsabilidades implícitas na geração de um filho, conforme o depoimento: "O momento em que eu mais me senti pai foi no nascimento. Quando eu peguei ele no colo pela primeira vez. Aí parece que vê que é verdade mesmo. Por que quando está na barriga, fica aquela coisa, por mais que a gente saiba, tudo. Mas quando nasce, que pega, é que a gente vê mesmo que tem que dar conta. (...) Por que o auge é quando (...) peguei ele na primeira vez, só não chorei por que tava com ele nos braços preocupado, sem saber pegar direito" (Guilherme).

A abordagem de paternidade revelada anteriormente nos discursos dos sujeitos, em que o(a) filho(a) é percebido(a) pelo homem desde a gestação, sendo o nascimento representado por
Guilherme como o auge e o momento em que mais se sentiu pai, convive com o modelo tradicional de pai, em que homens, embora diante da gestação como algo concretamente visível por longos meses, não constroem o sentimento de paternidade nesse período, conforme se lê nos depoimentos: "Depois do primeiro, quando o cabra já é pai já de um, aí vai-se embora (...) aí que vi o menino, aí pronto, daquele momento pronto. Às vezes o povo fala: a mulher está grávida, aí sou pai, aí não. O cara tem que ser pai depois que já está com o menino nos braços e tudo mais. Aí você pode dizer que é pai. Ninguém sabe na gravidez se é pai. Ninguém sabe o momento da gravidez, se vai ser, como vai ser, se vai nascer" (Aldo). "Eu me senti pai no primeiro dia que ele nasceu. Quando eu o vi. Antes, a gente sabe que está lá, mas não vê, não é a mesma coisa" (Tiago).

Esses depoimentos revelam que tomar conhecimento da gravidez não vincula, necessariamente, o homem ao papel de pai, mesmo quando esta ocorre no contexto de uma relação estável. Desse modo, a concepção de paternidade apresenta-se desvinculada da gravidez, parecendo ser um papel materno, sendo o(a) filho(a), nessa fase, propriedade exclusiva da mulher que o(a) "gera". Por sua vez, a ausência paterna é justificada pelo respeito à privacidade feminina, sendo considerada uma fase de domínio interior da mulher, em que o gestar e o parir são intrínsecos à sua responsabilidade. O pai não sabe como se situar internamente, cabendo-lhe o papel de observador passivo ${ }^{2}$. Diante dessa complexidade, a experiência da gravidez é vivida como um processo imaginário, no qual o parto representa a mudança radical: o ser pai nasce com o(a) filho(a) 15 .

Nesse sentido, a dificuldade de o pai sentir a gravidez como experiência compartilhada com mulher-filho(a) também pode ser relacionada com a reprodução ideológica da noção de homem/pai e mulher/mãe, historicamente construída e culturalmente preservada. Vinculada à história da gravidez no passado, tal noção é permeada por mitos e símbolos culturais, presentes desde a antiguidade, que vem direcionando os papéis sociais de gênero, excluindo o homem de uma participação mais efetiva neste processo ${ }^{8}$. Outrossim, no discurso de Aldo está a reafirmação do seu poder de macho e reprodutor, uma vez que certifica sua masculinidade ao ser pai mais uma vez. A concretude do nascimento do(a) filho(a) traz a renovação do atributo social da virilidade pela expressão nordestina que a simboliza e é usada pelo sujeito no seu discurso: o cabra (de o cabra macho, o cabra da peste).

Culturalmente, a maternidade está intimamente ligada ao cuidar e a manifestações afetivas 
para com os(as) filhos(as). A boa mãe é aquela que cuida, dá carinho e alimenta. Por sua vez, a paternidade segue caminho oposto ao da maternidade, sendo associada ao papel de provisão material, exortação, configurando o bom pai como aquele que não deixa faltar o alimento e dá lições para a vida aos(às) filhos(as). Esses comportamentos, frutos de estereótipos de gênero desvalorizam a participação do homem na gravidez por reproduzir a máxima de que gestação é "coisa de mulher", não havendo surpresa quando alguns pais precisam ver para crer. Agindo assim, os pais se excluem da responsabilidade pela vida do(a) filho(a) durante a gravidez, por não se sentirem parte dela.

Diante dessa construção social masculina e feminina, o ser marido e pai são diferentes e até certo ponto opostos ao ser esposa e mãe, já que, à medida que as mulheres se envolvem com os(as) filhos(as) e a casa, os homens se distanciam. Para o pai, a primeira responsabilidade social é com o provimento financeiro da família o que significa que ser pai não é só ter filhos, mas conseguir mantê-los. Com isso, o trabalho remunerado é a referência fundamental para o exercício da paternidade e sua contribuição emocional é raramente vista como de igual importância 1 .

À luz das discussões de gênero, a desconstrução desse modelo de pai tem ganhado espaço em eventos científicos sobre masculinidades e reprodução, a exemplo do 1o e 2o Seminário Internacional Homens, Sexualidade e Reprodução, ocorridos em São Paulo e Recife, respectivamente, e do $1^{\circ}$ Simpósio do Homem (São Paulo), nos quais homens e pais compartilharam, entre outras questões, a discussão entre gênero e poder e a necessidade de mudança de si próprios, dando espaço para refletir o impacto que o vazio afetivo provoca na sua relação com o(a) filho(a) e com a família 16. Essa dimensão pode ser percebida no discurso a seguir: "Eu verdadeiramente vim me sentir pai mesmo eu acho que a Nana devia ter entre cinco e seis anos. (...) Demorou pra eu assimilar aquela coisa de ser pai. (...) A gente começa a ver outros pais que davam bem mais atenção (...) eu comecei a ver realmente que eu estava ausente daquilo ali, aquela afeição de pai. (...) Com Nicole eu já tentei ser bem mais presente. (...) Eu acho que começa (...) quando começa a planejar a ter um filho (...) durante a gravidez é que você já sabe que está ali com o filho, que ele está ali dentro, que vai existir em todos os momentos, então como foi agora no caso de Nicole. (...) Então tive aquela vontade de já estar presente desde o primeiro momento de vida" (Tadeu).

Nesse discurso, identificamos uma mudança qualitativa na concepção e compreensão de Tadeu sobre paternidade, resultante da convi- vência com outros pais que se mostraram mais próximos afetivamente dos(as) filhos(as). A relação íntima e diária com a família não conseguiu gerar nesse pai sentimentos afetivos pela filha da primeira gravidez, perdendo a oportunidade de desenvolver relações sociais psicoafetivas significativas na construção da identidade da filha e do pai. A observação da vivência da paternidade dos outros pais levou-o a reconhecer a importância da dimensão subjetiva na sua relação com os(as) filhos(as). O sentimento de culpa gerado por essa observação, expressado por ele como sentir-se ausente motivou-o a repensar a função paterna e as relações pai-filha. Assim, sentir-se pai, passa a ser representado pelo extremo: momentos bem antes, quando do planejamento da gravidez.

Esse sentimento tardio é percebido na paternidade adolescente, em que o processamento do ser pai é lentamente construído a partir da vivência da relação pai-filho(a) 11, apesar de não ser exclusivo dessa fase. Em consonância com esse pensamento, a intenção do ser pai é diferente da intenção do ser mãe: o ser pai vem com a maturidade a partir de um projeto de constituir uma família e não do sonho de ter um(a) filho(a) apreendido em toda uma vida, como nas mulheres 7,17 .

O discurso atual de Tadeu valoriza a dimensão afetiva das relações sociais entre os cônjuges e os filhos desde a gravidez. Logo, ser pai implica, também, envolvimento emocional com quem ainda não nasceu. Significa produzir, no cotidiano, oportunidades de relações familiares solidárias, que envolvem o atendimento das necessidades de cada um e da família como um todo. O pai tradicional, aquele que garante a subsistência da família manifesta-se também nesse sujeito da pesquisa, mas não representa a figura do pai resgatada, anos depois, com a gestação da segunda filha.

Sobre sentimentos vividos tardiamente pelo pai, Corneau 18 argumenta que, muitas vezes, a relação mãe-filho(a), estabelecida intimamente desde a gravidez, é prolongada para além do nascimento, levando o pai a viver a paternidade anos mais tarde, pois: “... a mulher toma posse, como se fosse um bem pessoal, quando o projeto era fazer um filho a dois. Ou essa situação lhe convém (...) e ele se resigna, ou então fica frustrado e se torna um 'pai impedido'...” 18 (p. 33).

Essa é uma posição social questionável à luz da abordagem de gênero, porque não foram as mulheres que decidiram sobre a ordem estabelecida. Além do mais, há alguns ganhos secundários para os homens em se manterem afastados da gestação, como a possibilidade de se colocarem "mais distantes" de prováveis sofrimentos e se sentirem menos "culpados", além de dispor de 
mais tempo mental para elaborar as transformações que estão ocorrendo ao seu redor. Porém, uma vez superados os bloqueios, tais mecanismos psicológicos tornam-se desnecessários e o pai verdadeiro emerge e vai procurar viver com a segunda filha o que não teve oportunidade de viver com a primeira.

A experiência da paternidade depende também da relação vivida entre pai e filho, no passado, que influencia o modo como o homem compreende e assume a sua masculinidade. Para sua realização como pai, ele busca referências em seu próprio pai 10,11,19, encontrando, na maioria das vezes, o modelo de pai distante e pouco envolvido afetivamente, referencial de masculinidade ainda hegemônico. O filho incorpora esse modelo, construindo uma subjetividade distanciada da valorização do afeto, ao mesmo tempo em que tem na sua mãe o exemplo de cuidado. Reproduz-se, portanto, a relação pai-mãe-filho, tal como determinada socialmente e experimentada na sua vivência, evidenciando um mecanismo ideológico de reprodução do conservadorismo do status quo.

Embora não tenha sido investigado mudanças nos sentimentos paternos ao longo do processo de crescimento e desenvolvimento dos(as) filhos(as), ao considerarmos a significativa variação de idade, vinte dias a oito anos, é possível afirmar que a distância temporal da gravidez e do nascimento parecem não ter provocado alterações importantes nos sentimentos paternos.

Em síntese, os participantes do estudo apresentaram, em seus depoimentos, vivências de paternidade que ora se ancoram no modelo de pai tradicional, ora apontam a perspectiva de um novo modelo de ser pai: o "novo pai”. A perspectiva de mudança do modelo tradicional de pai, que se revelou na minoria dos discursos dos sujeitos do estudo, é significativa porque aponta possibilidades de transformação das relações sociais de gênero, o que implica a revisão de atributos sociais maternos e paternos.

\section{Considerações finais}

A posição social dos sujeitos participantes deste estudo frente ao momento em que se sentiram pais, a partir da notícia da gravidez, apresentase sob formas diferentes de sentir a paternidade. O modelo de paternidade em que o homem mantém-se distante da vivência da gestação, assumindo-se como pai pela função de provedor, convive com o do homem que busca ser um "novo pai”, cujo vínculo afetivo é valorizado desde a gestação, representando possibilidades efetivas de rupturas com o modelo tradicional de pai.
Aqueles que se aproximam do modelo tradicional, em razão do modo de sentir a paternidade, entendem-na como uma fase que tem início na concretude do nascimento da criança, permanecendo distantes e apáticos na gestação, por não se sentirem parte dela. Os sujeitos participantes do estudo, em sua maioria, apresentaram em seus discursos, esse modelo tradicional de pai.

No entanto, o modelo de paternidade mais envolvida, em sua intensidade afetiva e solidária, também esteve presente entre os homens entrevistados, indicando que a relação familiar vivida na atualidade tem modificado qualitativamente o significado da paternidade. Nesse sentido, o "novo pai" visita o pai tradicional, mas afasta-se dele, dotando a paternidade de sentido mais amplo, percebendo-a desde a gravidez, iniciando ainda nessa fase a construção de vínculos afetivos que se firmarão com o nascimento. Esse movimento dialético faz emergir reflexões nos sujeitos acerca de suas próprias concepções sobre o ser pai abrindo possibilidades de (des)construir a paternidade incorporada a partir das relações sociais desde menino, sobretudo com o próprio pai.

Desse modo, o sentir-se pai pode ser concebido e vivido como um direito e um dever. Direito do homem, para expressar seus sentimentos e participar dos cuidados sem o estigma da afirmação sexual. Dever, pela necessidade do filho de ter um pai participativo dos cuidados e da afetividade e pela necessidade de divisão de tarefas entre homens e mulheres. Assim, afirmamos: é pela vivência, superação das contradições e expressão das experiências afetivas mais profundas que o homem deve se tornar e vivenciar o ser pai.

Todavia, essa mudança não depende somente do desejo intrínseco do homem em ser um "novo pai” ou um "pai contemporâneo". É oportuno ressaltar que as responsabilidades sociais impostas ao pai provedor também lhes trazem prejuízos no campo da subjetividade, pois mesmo o homem tendo mais possibilidades de ação especialmente no campo das relações familiares, tais ações são exercidas sobre rígidos parâmetros 20. Assim, a questão da paternidade ultrapassa os limites da família e se torna um campo concreto de discussão no âmbito da saúde sexual e reprodutiva e da saúde coletiva.

No tocante à saúde sexual e reprodutiva, a paternagem e a maternagem precisam ser compreendidas como responsabilidade da díade homem-mulher e devem ser exercidas de forma compartilhada. Na atenção básica à saúde, há de se apreender a figura do pai como um dos sujeitos diretamente envolvidos na gestação, valorizando que a sua construção social dita a paternidade, mas não o engessa nela, existindo 
diversas modalidades de ser pai 21 . O exercício da paternidade pode ser a porta de entrada do homem no campo dos cuidados, de si próprio, dos(as) filhos(as) e da companheira. Nesse senti-

\section{Resumo}

O pouco envolvimento de parceiros com filhos(as) desde a gestação é freqüentemente relatado por mulheres grávidas e puérperas que resultam em tensões e conflitos. Frente a essa realidade, foi realizado um estudo com o objetivo de compreender a emergência do sentimento de paternidade em homens que a vivenciam. A pesquisa foi desenvolvida sob abordagem qualitativa e enfoque teórico de gênero. O universo empírico do estudo foi constituído por dez homens, contactados em ambulatório de puericultura, sendo os dados produzidos por meio de entrevista semi-estruturada. Os depoimentos dos sujeitos do estudo foram analisados pela técnica de análise do discurso, cujo princípio básico é reconhecer no texto seus níveis mais abstratos, identificados por temas que, organizados em blocos de significação, permitem a construção de categorias empíricas. A posição social dos sujeitos do estudo frente ao momento em que se sentiram pais revela que o modelo em que homens assumem-se como pais pela função de provedor convive com o modelo do homem que busca ser um "novo pai", cujo vínculo afetivo com o(a) filho(a) se inicia na gestação, representando ruptura com a paternidade tradicional.

Paternidade; Saúde Reprodutiva; Identidade de Gênero do, a educação, a informação e a atenção à saúde permeada pela abordagem de gênero podem gerar mudanças nas concepções e no exercício do ser pai e do ser mãe na sociedade.

\section{Colaboradores}

W. M. F. Freitas participou da revisão de literatura, elaboração da metodologia, realização das entrevistas, análise dos resultados e redação do artigo final. E. A. C. Coelho e A. T. M. C. Silva colaboraram na revisão da literatura, análise dos resultados, redação e revisão do artigo final. 


\section{Referências}

1. Chodorow N. Psicanálise da maternidade: uma crítica a Freud a partir da mulher. Rio de Janeiro: Editora Rosa dos Tempos; 1990.

2. Nolasco S. O mito da masculinidade. 2a Ed. Rio de Janeiro: Editora Rocco; 1995.

3. Centa ML. Experiências vivenciadas pelos homens durante a primeira gravidez e parto de suas mulheres [Dissertação de Mestrado] Florianópolis: Curso de Mestrado em Ciências da Enfermagem, Universidade Federal de Santa Catarina; 1981.

4. Freitas WMF. Experiências vivenciadas por casais durante a gestação e parto [Monografia de Especialização]. Recife: Instituto Materno Infantil de Pernambuco; 2001.

5. Freitas WMF. Significado da paternidade para homens que a vivenciam: um olhar de gênero [Dissertação de Mestrado]. João Pessoa: Programa de Pós-Graduação em Enfermagem, Universidade Federal da Paraíba; 2004.

6. Fiorin JL. Linguagem e ideologia. 7ạ Ed. São Paulo: Editora Ática; 2003.

7. Costa RG. Reprodução e gênero: paternidades, masculinidades e teorias da concepção. Estudos Feministas 2002; 10:339-56.

8. Piccinini CA, Moura MLS, Ribas AFP, Bosa CA, Oliveira EA, Pinto EB, et al. Diferentes perspectivas na análise da interação pais-bebê/criança. Psicol Reflex Crit 2001; 14:469-85.

9. Piccinini CA, Silva MR, Gonçalves TR, Lopes RS, Tudge J. O envolvimento paterno durante a gestação. Psicol Reflex Crit 2004; 17:303-14.

10. Gomes AJS, Resende VR. O pai presente: o desvelar da paternidade em uma família contemporânea. Psicol Teor Pesqui 2004; 20:119-25.

11. Trindade ZA, Menandro MCS. Pais adolescentes: vivência e significação. Estud Psicol (Natal) 2002; 7:15-23.
12. Giffin K. Exercício da paternidade: uma pequena revolução. In: Silveira P, organizador. Exercício da paternidade. Porto Alegre: Editora Artes Médicas; 1998. p. 75-80.

13. Jablonski B. Paternidade hoje: uma metanálise. In: Silveira P, organizador. Exercício da paternidade. Porto Alegre: Editora Artes Médicas; 1998. p. 121-9.

14. Badinter E. Um amor conquistado: o mito do amor materno. Rio de Janeiro: Editora Nova Fronteira; 1985.

15. Maciel AA. Ser/estar pai: uma figura de identidade [Dissertação de Mestrado]. São Paulo: Faculdade de Saúde Pública, Universidade de São Paulo; 1994.

16. Costa RG. De clonagens e de paternidades: as encruzilhadas do gênero. Cadernos Pagu 1998; 11:157-99.

17. Arilha M. Homens: entre a "zoeira" e a "responsabilidade". In: Arilha M, Unbehaum SG, Medrado B, organizadores. Homens e masculinidades: outras palavras. 2a Ed. São Paulo: ECOS/Editora 34; 2001. p. 51-78.

18. Corneau G. Pai ausente, filho carente: o que aconteceu com os homens? São Paulo: Editora Brasiliense; 1991.

19. Ramires VR. O exercício da paternidade hoje. Rio de Janeiro: Editora Rosa dos Tempos; 1997. (Coleção Gênero, 2).

20. Torrão Filho A. Uma questão de gênero: onde o masculino e o feminino se cruzam. Cadernos Pagu 2005; 24:127-52.

21. Schraiber LB, Gomes R, Couto MT. Homens e saúde na pauta da saúde coletiva. Ciênc Saúde Coletiva 2005 ; 10:7-17.

Recebido em 04/Mai/2005

Versão final reapresentada em 28/Dez/2005

Aprovado em 30/Mar/2006 